\title{
Critical Conditions and Energy Transfer Characteristics of the Failure Process of Coal-Rock Combination Systems in Deep Mines
}

\author{
Haitao Sun, ${ }^{1,2}$ Linchao Dai $\mathbb{D}^{1,2}$ Yanbao Liu, ${ }^{1,2}$ and Hongwei Jin ${ }^{3}$ \\ ${ }^{1}$ State Key Laboratory of the Gas Disaster Detecting, Preventing and Emergency Controlling, Chongqing 400037, China \\ ${ }^{2}$ China Coal Technology and Engineering Group Chongqing Research Institute, Chongqing 400037, China \\ ${ }^{3}$ School of Safety Engineering, Xi'an University of Science and Technology, Xi'an, Shanxi 710054, China
}

Correspondence should be addressed to Linchao Dai; dailinchao@126.com

Received 7 December 2020; Revised 21 December 2020; Accepted 4 February 2021; Published 25 February 2021

Academic Editor: Timothy S. Collett

Copyright (c) 2021 Haitao Sun et al. This is an open access article distributed under the Creative Commons Attribution License, which permits unrestricted use, distribution, and reproduction in any medium, provided the original work is properly cited.

With the steady increase in the size, intensification, and modernization of coal production enterprises, the deep coal resources in large coal bases are gradually entering the mining stage. When the coal mining reaches the deep zone, the interactions between various underground dynamic hazards begin to occur. These interactions are affected by the engineering geological environment and can lead to the occurrence of severe compound hazards. When coal and gas outbursts occur and destabilize the mining area, the high geostress causes the multiphysical coupling effect of the laminated overburden system to become more pronounced. Therefore, we analyzed the development path of a coal-rock system under instability conditions from the perspective of coal-rock coupling, constructed a model of the coal-rock combination system's structure, and proposed three directions (i.e., strain softening, limit equilibrium, and dynamic instability) for the development of coal-rock system instability. Then, we established a model for the critical conditions of the system's failure process and elucidated that the release of the rock's elastic energy promoted the instability of the coal. Furthermore, we verified the established critical conditions through laboratory tests on a coal-rock combination structure and obtained the patterns of the rock energy transferring into the coal seam during the instability failure process of the coal-rock combination structure. When the coal-rock combination structure failed, the rock strain reached its maximum value and the strain rebound phenomenon occurred. The stored elastic strain energy released by the rock into the combination system accounted for $26 \%$ to $53 \%$ of the accumulated energy in the rock itself, and the released elastic energy and the new surface area of the crushed coal sample followed a logarithmic relationship. The findings of this study provide theoretical support for the identification and quantitative analysis of instability due to the dynamic hazards of coal-rock gas in deep mines.

\section{Introduction}

As the depth of coal mining increases, deep mining presents a complex mechanical environment that has been described as "three highs and one disturbance," i.e., high geostress, high geotemperature, high osmotic pressure, and strong mining disturbance, making the rock's mechanical behavior and the hazard characteristics in the deep zone significantly different from those in the shallow zone [1-5]. When coal mining reaches the deep zone, interactions begin to occur between the various underground dynamic hazards in the coal mine, resulting in compound hazards such as the rockburst- outburst compound dynamic hazard of coal-rock [6, 7], which is caused by the combined actions of multiple factors such as high stress, high gas pressure, and a hard roof under deep conditions and poses a serious problem in deep coal mining projects. Coal-rock dynamic hazards in deep mines are affected by the special engineering geological environment, which involves complex mechanisms of hazard formation, occurrence, and development. Numerous basic studies have been carried out on this topic. Several studies used the dynamic failure characteristics of rock specimens determined using a flexible testing machine to describe rockburst and to formulate the stiffness theory of rockburst $[8,9]$. Based on 
the energy criterion of rockburst and coal and gas outbursts, other studies established a unified instability theory of rockburst and coal and gas outbursts and discussed the mechanism of the induction and transformation of dynamic hazards [10-16]. Compound dynamic hazards have been reclassified $[17,18]$. Numerous studies have been conducted on the rockburst tendency, damage precursor information, acoustic emission characteristics, and electromagnetic radiation signals of coal-rock combinations, and the deformation characteristics and strength criteria of different coal-rock combinations have been discussed [19-28].

The deep high-stress environment significantly increases the risk of rockbursts in coal seams, roofs, and their combination structures. The elastic energy stored in coal-rock structures with a rockburst tendency is an important energy source for the occurrence of compound dynamic hazards. This elastic energy is used in the process of coal and rock dynamic hazards. The patterns of the accumulation, transformation, and dissipation of the elastic energy in the process of coal-rock dynamic hazard formation directly determine the probability and intensity of the hazards [29]. The experimental study of coal-rock combinations from an energy perspective helps to fundamentally investigate the failure mechanism of coal-rock combinations. When the coal-rock combination specimen yields, the proportion of the dissipated energy increases while that of the elastic energy decreases [30, 31]. Chen et al. [32] conducted uniaxial loading tests on coal-rock combinations with different proportions and found that the energy of the coal-rock sample is mainly distributed in the weak coal-rock seam, and regardless of the specific type of the coal-rock combination, the portion of energy in the coal is greater than $50 \%$. Song et al. [33] carried out the conventional uniaxial and uniaxial cyclic loading tests on three types of samples (i.e., coal, rock, and coal-rock combinations) to reveal the failure modes and energy evolution law of underground coal during the mining process and found that the elastic energy stored in coal-rock combinations played a dominant role in the distribution of all input energy, accounting for more than $80 \%$ of it. And with the increase in cycle index, both the elastic energy stored in the sample and the dissipated energy increased in a quadratic function, and the failure process became more intense.

During the occurrence of coal-rock dynamic hazards in deep mines, the instability failure of coal-rock combinations is clearly influenced by the lithological characteristics of the coal seam and the roof, and the corresponding failure process is caused by the comprehensive effect of the roof-coal seam-floor system. Therefore, we simplified the coal-rock system to a rock+coal combination sample structure. Different types of coal-rock combination sample structures were constructed, and laboratory tests were carried out to investigate the patterns of accumulation, transformation, and dissipation and the quantitative characteristics of the energy in the rock sample and coal sample during the deformation and failure process of the coal-rock combination samples with different characteristics (i.e., combination types and lithologies). The mechanical criterion and energy failure characteristics of the compound failure of the bursting coal-rock combination sample structure were obtained to guide the prediction and the prevention and control of rockburst-outburst compound dynamic hazards in deep mines.

\section{Analysis of Coal-Rock Combination System in Deep Mines}

The roof-coal seam system in deep mines reaches the ultimate mechanical equilibrium state and fails under external loads and changes in the internal physical and mechanical properties. When the elastic strain energy accumulated by the system exceeds the energy consumed by the system at failure, intense rockburst occurs as the crushed coal-rock bodies are subjected to excess energy, resulting in coal-rock dynamic hazards. Because the elastic modulus of rock is much larger than that of coal, the strain of the rock part of the sample is much smaller than that of the coal part during the compression process. This leads to the failure of the system, which is manifested by the failure and fragmentation of the coal $[34,35]$. During this process, from the system being compressed to the coal reaching its mechanical equilibrium state, which leads to the ultimate failure of the sample, both the coal and rock deform, and energy is accumulated continuously in the system. When the energy accumulated in the system reaches the limit the system can bear, the coal-rock combination structure undergoes instability failure, which causes the energy to be released rapidly, resulting in the deformation failure of the coal at the bottom. In the above process, the upper rock deforms under compression, and energy is continuously accumulated in the rock. Part of the accumulated energy acts on the rock itself, compacting the primary pores and fractures, while the other part of the energy is stored in the form of elastic energy. When the combination structure undergoes instability failure, the coal fails, the strength of the system decreases sharply, and the rock is unloaded. This passive unloading causes the strain rebound phenomenon in the rock; that is, the strain of the rock decreases. The elastic strain energy stored in the rock itself is released instantaneously, and part of the released elastic energy acts on the coal, exacerbating the failure of the coal and increasing the crushing degree of the coal. When the coal undergoes instability failure, it bears not only the effect of the accumulated energy of the system under the external load but also the effect of the elastic strain energy released by the rock. In different combination structures, the rock has different effects on the elastic strain energy of the coal and on the degree of aggravation of the coal failure.

Taking the coal-rock combination sample with an upper rock and lower coal structure as the research object, the roofcoal seam structure in a deep mine was simulated, and the model of the interaction between the coal seam and the rock layer in a deep mine was simplified using the similar model method, as shown in Figure 1. It is of great significance to analyze the failure characteristics and mechanical properties of different combination samples under uniaxial conditions, to investigate the quantitative patterns of energy conversion during the instability failure of combination samples, and to elucidate the mechanisms of compound dynamic hazards under deep mine conditions from an energy perspective. 


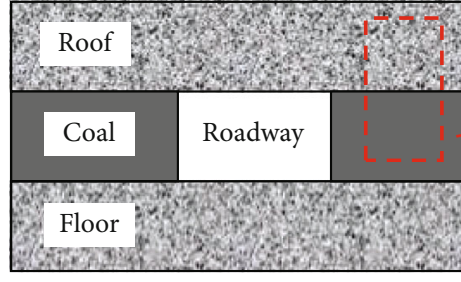

Geological engineering model

(a)

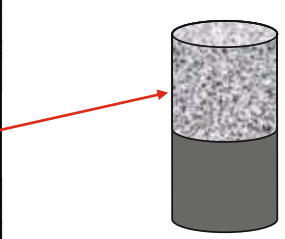

Simplified model

(b)
Figure 1: The structural mechanics model of coal-rock combination: (a) geological engineering model; (b) simplified model.

\section{Critical Conditions for Instability Failure of Coal-Rock Combination System}

In a coal-rock combination structure, the coal and rock have different physical and mechanical properties. The coal, the large number of microfractures and pores inside the coal, and the coal-rock interface jointly constitute the soft part of the combination structure, and the rock constitutes the hard part [36]. The coal-rock combination sample structure exhibits nonlinear mechanical properties, and the critical conditions for its instability failure and the criterion of the failure state are related to the physical and mechanical properties of the coal and the rock.

3.1. Criterion of the Failure State. To objectively describe the stress-strain relationship of the coal-rock combination structure under vertical mining stress during the advancement of the driving face, a simplified uniaxial loading model of the coal-rock combination structure was established, as shown in Figure 2.

Assuming that $a$ and $b$ are the rock block and coal block, respectively, each of which has an elasticity-strain softening constitutive relationship, the constitutive equation for the coal-rock combination material is shown in Figure 3 and the following equation:

$$
\sigma= \begin{cases}E \varepsilon, & -\infty<\varepsilon \leq \varepsilon_{\mathrm{c}}, \\ \sigma_{\mathrm{c}}-E_{\mathrm{t}}\left(\varepsilon-\varepsilon_{\mathrm{c}}\right), & \varepsilon_{\mathrm{c}}<\varepsilon \leq \varepsilon_{\mathrm{r}}, \\ \sigma_{\mathrm{r}}, & \varepsilon_{\mathrm{r}}<\varepsilon \leq+\infty,\end{cases}
$$

where $E$ is the elastic modulus of the material and $E_{\mathrm{t}}$ is the slope of the descending section of the curve, which is taken as a positive value. $\sigma_{\mathrm{c}}$ is the uniaxial compressive strength of the material; and $\varepsilon_{\mathrm{c}}$ is the compressive strain of the material when it reaches the uniaxial compressive strength, $\varepsilon_{\mathrm{c}}=\sigma_{\mathrm{c}} / E$. $\sigma_{\mathrm{r}}$ and $\varepsilon_{\mathrm{r}}$ are the strength and strain, respectively, of the material when it essentially loses its load-bearing capacity, that is, the starting point of the zero residual strength stage.

Suppose that the displacement at the top of $a$ (i.e., the overall displacement of the combination sample) is $u$. The peak strains of $a$ and $b$ are $\varepsilon_{c a}$ and $\varepsilon_{c b}$, respectively. Before $b$ reaches the peak strength, both $a$ and $b$ are in the linear elastic stage, that is, in the first part of the constitutive equation.

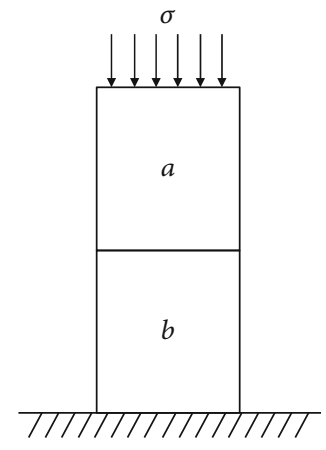

Figure 2: Coal-rock combination uniaxial loading model.

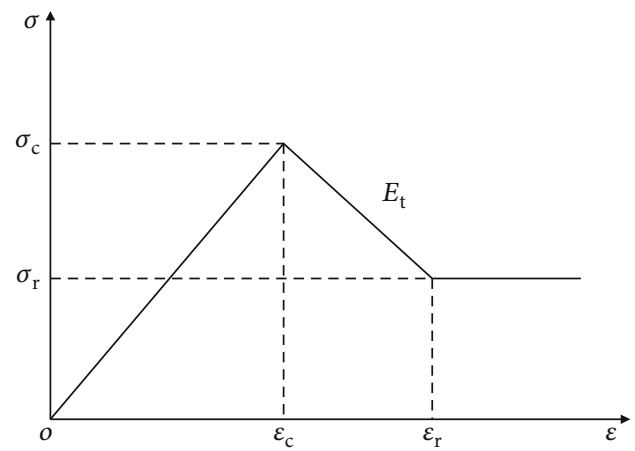

FIgURE 3: The elasticity-strain softening constitutive relationship.

The following relationship can be obtained by assuming that the stresses on $a$ and $b$ are equal during the compression:

$$
\left\{\begin{array}{l}
E_{a} \varepsilon_{a} S_{a}=E_{b} \varepsilon_{b} S_{b} \\
\varepsilon_{a} l_{a}+\varepsilon_{b} l_{b}=u
\end{array}\right.
$$

where $E_{a}$ and $E_{b}$ are the elastic moduli of the rock and coal, respectively; $\varepsilon_{a}$ and $\varepsilon_{b}$ are the strains of the rock and coal, respectively; $S_{a}$ and $S_{b}$ are the cross-sectional areas of the two blocks, respectively; and $l_{a}$ and $l_{b}$ are the heights of the corresponding rock block $a$ and coal block $b$, respectively.

According to Equation (2), the stress-displacement relationship of the coal-rock combination structure in the linear elastic stage is

$$
\sigma=E_{a} \varepsilon_{a}=\frac{E_{a} E_{b} S_{b}}{E_{a} S_{a} l_{b}+E_{b} S_{b} l_{a}} u,
$$

where $\sigma$ is the stress of the combination structure in the elastic stage. In this stage, the overall strain of the combination structure increases as the external load increases, and the system is in a stable state.

When the axial load gradually increases to a certain value, in the loading model, $b$ reaches its peak strength first, and the failure of the combination sample occurs in the coal block. At this time, the constitutive relationship of $b$ in the combination structure is expressed by the second part of the equation, that is, the slope section in Figure 3. a still satisfies the 
characteristics of the elastic stage, and the corresponding relationship is as follows:

$$
\left\{\begin{array}{l}
E_{a} \varepsilon_{a} S_{a}=\left[\sigma_{c b}-E_{\mathrm{t} b}\left(\varepsilon_{b}-\varepsilon_{\mathrm{c} b}\right)\right] S_{b} \\
\varepsilon_{a} l_{a}+\varepsilon_{b} l_{b}=u
\end{array} .\right.
$$

Substitution of $\varepsilon_{c b}=\sigma_{c b} / E_{b}$ into Equation (4) gives

$$
\varepsilon_{a}=\frac{E_{b} S_{b} \sigma_{\mathrm{cb}} l_{b}+E_{\mathrm{t} b} S_{b} \sigma_{\mathrm{cb}} l_{b}-E_{b} S_{b} E_{\mathrm{t} b} u}{\left(E_{a} S_{a} l_{b}-E_{\mathrm{t} b} S_{b} l_{a}\right) E_{b}}
$$

Finally, the stress of the coal-rock combination structure is

$\sigma=E_{a} \varepsilon_{a}=\frac{E_{a}}{E_{b}}\left(\frac{\left(E_{b} S_{b} \sigma_{c b} / l_{a}\right)+\left(E_{\mathrm{t} b} S_{b} \sigma_{c b} / l_{a}\right)}{\left(E_{a} S_{a} / l_{a}\right)-\left(E_{t b} S_{b} / l_{b}\right)}-\frac{E_{b} E_{\mathrm{t} b} S_{b} / l_{a} l_{b}}{\left(E_{a} S_{a} / l_{a}\right)-\left(E_{\mathrm{tb}} S_{b} / l_{b}\right)} u\right)$.

When the external load causes $b$ in the combination structure to fail completely, the combination structure completely loses its bearing capacity. $b$ is in the third part of the constitutive equation, while $a$ is still in the elastic stage, and the following relationship applies:

$$
\sigma=\sigma_{\mathrm{r} b}
$$

where $\sigma_{\mathrm{r} b}$ is the strength of coal block $b$ when it loses its bearing capacity.
The failure state of the combination structure under uniaxial conditions can be divided into three stages, namely, the elastic (nonfailure) stage, the failure stage, and the postfailure stage, based on the constitutive equation of the coal-rock combination structure constructed under uniaxial conditions. Taking $b$ with its relatively low strength in the structure as the research object and using the relative relationship between the ratio of the strain $\varepsilon$ of $b$ in the uniaxial compression process to the strain $\varepsilon_{\mathrm{c}}$ when it achieves its uniaxial compressive strength and the strain $\varepsilon_{\mathrm{r}}$ when it just completely loses its load-bearing capacity, the characteristics of each stage are as follows:

(1) When $\varepsilon \leq \varepsilon_{c}$, the combination structure is in the elastic stage, and neither the coal nor the rock fails. As the external load increases, the strain of the coal and rock increases

(2) When $\varepsilon_{\mathrm{c}}<\varepsilon \leq \varepsilon_{\mathrm{r}}$, the combination structure is in the failure stage. $\varepsilon_{\mathrm{c}}$ is the starting point of the instability failure of the combination structure, and it corresponds to the maximum stress point of the combination structure. After this point, the coal block fails and the stress decreases as the strain increases, exhibiting a sharp drop in the bearing capacity of the combination structure

(3) When $\varepsilon_{\mathrm{r}}<\varepsilon$, the combination structure has completely lost its bearing capacity

3.2. Analysis of the Critical Conditions of Failure. According to Equations (3), (6), and (7), the expression or the stress on the coal-rock combination structure is

$$
\sigma= \begin{cases}\frac{E_{a} E_{b} S_{b}}{E_{a} S_{a} l_{b}+E_{b} S_{b} l_{a}} u, & -\infty<\varepsilon_{b} \leq \varepsilon_{\mathrm{c} b}, \\ \frac{E_{a}}{E_{b}}\left(\frac{\left(E_{b} S_{b} \sigma_{\mathrm{c} b} / l_{a}\right)+\left(E_{\mathrm{t} b} S_{b} \sigma_{\mathrm{cb}} / l_{a}\right)}{\left(E_{a} S_{a} / l_{a}\right)-\left(E_{\mathrm{t} b} S_{b} / l_{b}\right)}-\frac{E_{b} E_{\mathrm{t} b} S_{b} / l_{a} l_{b}}{\left(E_{a} S_{a} / l_{a}\right)-\left(E_{\mathrm{t} b} S_{b} / l_{b}\right)} u\right), & \varepsilon_{\mathrm{c} b}<\varepsilon_{b} \leq \varepsilon_{\mathrm{r} b}, \\ \sigma_{\mathrm{r} b}, & \varepsilon_{\mathrm{r} b}<\varepsilon_{b} \leq+\infty .\end{cases}
$$

Based on Equation (8), when the strain of $b$ is within a certain range, the conditions of the instability failure of the overall combination sample structure can be obtained, as shown in Figure 4.

(1) For the first equation (section $\mathrm{OA}$ in Figure 4), every part of the combination structure is in the elastic stage. As the load on the combination structure increases, the displacements of the coal and rock increase, but the system remains in a stable state. The peak stress of this section is the peak stress $\sigma_{c b}$ of $b$, which has a relatively low strength

(2) For the second equation, if $\left(E_{a} S_{a} / l_{a}\right)-\left(E_{\mathrm{t} b} S_{b} / l_{b}\right)>0$, the coefficient $u$ is negative, and the combination structure is characterized by strain softening (section $\mathrm{AB}$ in Figure 4). In this stage, external work must be done to the system to increase the degree of damage to the system. However, if the external energy is input at a very low rate, even if the system can withstand less and less stress, the combination structure will not suddenly lose its bearing capacity, and thus, the system remains in a stable state

If $\left(E_{a} S_{a} / l_{a}\right)-\left(E_{\mathrm{t} b} S_{b} / l_{b}\right)<0$, the coefficient $u$ is positive, and the equilibrium path of the system corresponds to section $\mathrm{AD}$ in Figure 4. The external load on the system decreases continuously, and the displacement at the top of the system increases (with downward displacement, i.e., the top surface of the system moving upward, which is negative); that is, the rebound phenomenon occurs. This means that while the system gradually loses its bearing capacity, it performs external work, and the elastic strain energy accumulated in the combination structure is released. The 


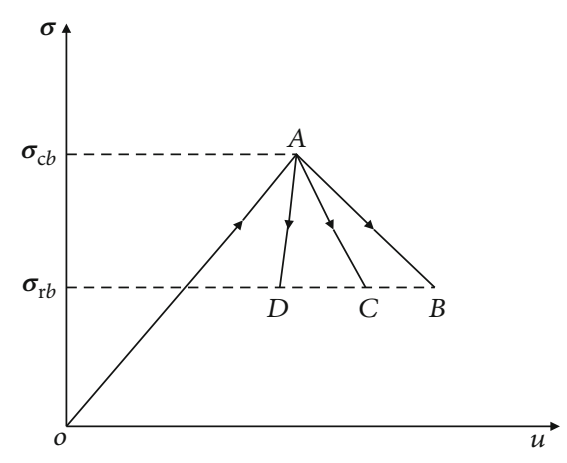

FIgURE 4: Balance path of coal-rock combination under uniaxial compression.

equilibrium path of section $\mathrm{AD}$ is from $\mathrm{A}$ to $\mathrm{D}$; that is, the system performs external work and loses its bearing capacity. When the external constraints on the system are sufficiently small and thus, the system is unable to effectively perform external work, in addition to acting on the coal, the internal elastic strain energy may also be directly transformed into the kinetic energy of the rock block. Thus, the system will rapidly lose its stability and exhibit a dynamic effect.

If $\left(E_{a} S_{a} / l_{a}\right)-\left(E_{\mathrm{t} b} S_{b} / l_{b}\right)=0$, the coefficient $u$ is negative infinity, and the equilibrium path of the system corresponds to section AC in Figure 4. In this case, the system is in a critical state. This means that as long as work is done externally by or to the system, it immediately loses all bearing capacity; that is, the combination structure is in a state of limit equilibrium.

(3) For the third equation, the equilibrium path of the system corresponds to the back section of point B in Figure $4 . b$ in the combination structure has already undergone instability failure, and the strength of the sample is reduced. The external load is the residual strength of $b$.

According to the above analysis, $E_{a} S_{a} / l_{a}$ is the stiffness of $a$ in the combination structure and characterizes the ability of $a$ to resist elastic deformation when it is stressed during the elastic stage; and $E_{\mathrm{t} b} S_{b} / l_{b}$ is the stiffness of $b$ after failure and characterizes the ability of $b$ to maintain its bearing capacity when displacement occurs during the strain-softening stage. The correspondence between $\left(E_{a} S_{a}\right.$ $\left./ l_{a}\right)-\left(E_{\mathrm{t} b} S_{b} / l_{b}\right)$ and 0 can be used as the critical condition for the combination structure in different failure states, and the critical point of instability failure of the combination structure can be determined accordingly. When its value is zero, the system is in a state of limit equilibrium. When its value is greater than zero, the damage degree of the combination structure increases if it is subjected to a large external load. When its value is less than zero, the damage to the combination structure is attributed to the combined actions of the external load and the rock block rebound energy, which may cause rapid instability failure.

3.3. Coal-Rock Elastic Modulus Correction Parameters. Due to the large number of pores and fractures in the coal, rock, and combination samples, they are strongly heterogeneous and anisotropic. Therefore, the elastic moduli of the rock samples and coal samples obtained in the experiment are not unique values but are dynamic variables related to the loading process. Considering the weakening effect of the coal-rock interface and the microfractures and pores inside the rock and coal on the elastic modulus and taking into account the influence of data discreteness due to the low number of experiments, the elastic modulus parameters of the coal and rock should be corrected in the data analysis.

In the coal-rock combination sample structure system, the rock is regarded as the hard part and is equivalent to a hard spring, while the coal is treated as the soft part and is equivalent to a soft spring, both of which satisfy Hooke's law, i.e., the two-part Hooke's model (TPHM) [37-41]. The structure of the coal-rock combination sample is a TPHM, in which the nonlinear behavior of the combination sample during the loading process is discussed. Using the basic assumptions, the coal and rock in the coal-rock combination sample are regarded as a soft body and a hard body, respectively. The force deformation process is shown in Figure 5. In Figure 5, $F$ is the external force; $H_{\mathrm{R}}$ and $H_{\mathrm{C}}$ are the heights of the rock and coal, respectively, in the coal-rock combination before loading; $D_{\mathrm{R}}$ and $D_{\mathrm{C}}$ are the diameters of the rock and coal, respectively, in the coal-rock combination before loading; $h_{\mathrm{R}}$ and $h_{\mathrm{C}}$ are the heights of the rock and coal, respectively, in the coal-rock combination after loading; and $d_{\mathrm{R}}$ and $d_{\mathrm{C}}$ are the diameters of the rock and coal, respectively, in the coal-rock combination after loading. When only uniaxial compression and axial strain are considered, the change in the diameter of the combination sample before and after loading can be ignored, i.e., $D_{\mathrm{R}=} d_{\mathrm{R}}$ and $D_{\mathrm{C}=} d_{\mathrm{C}} . \Delta$ is the displacement of the coal-rock combination specimen before and after loading.

Under external force $F$, the coal-rock combination will undergo elastic deformation. According to Hooke's law,

$$
\begin{aligned}
& d \sigma_{\mathrm{R}}=m_{\mathrm{R}} E_{\mathrm{R}} d \varepsilon_{\mathrm{R}}, \\
& d \sigma_{\mathrm{C}}=m_{\mathrm{C}} E_{\mathrm{C}} d \varepsilon_{\mathrm{C}},
\end{aligned}
$$

where $\sigma_{\mathrm{R}}$ and $\sigma_{\mathrm{C}}$ are the stresses applied to the upper rock sample and the coal sample, respectively; $E_{\mathrm{R}}$ and $E_{\mathrm{C}}$ are the elastic moduli of the rock sample and coal sample, respectively; $\varepsilon_{\mathrm{R}}$ and $\varepsilon_{\mathrm{C}}$ are the axial strains of the rock sample and the coal sample, respectively; and $m_{\mathrm{R}}$ and $m_{\mathrm{C}}$ are the correction coefficients for the elastic moduli of the rock sample and the coal sample, respectively.

In the TPHM, the rock represented by a hard spring and the coal represented by a soft spring deform under the same force $F$. There are a large number of fractures in the coal, a considerable number of which are consistent with the direction of the principal stress and will develop and propagate as the principal stress increases, thereby leading to the failure of the coal and resulting in nonlinear elastic deformation or inelastic deformation. 


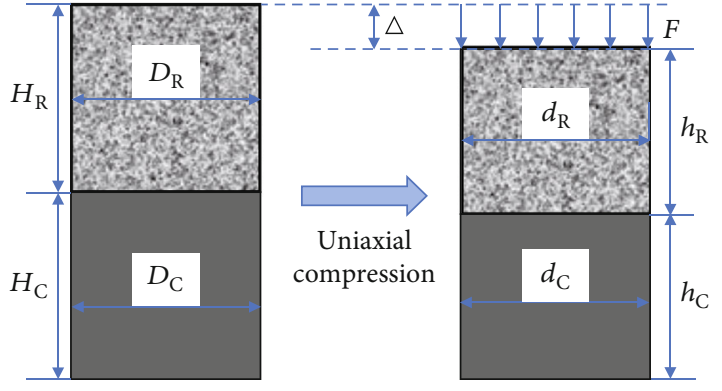

FIGURE 5: Schematic diagram of the deformation of the coal-rock combination under an external force.

The respective strains of the rock and coal in the combination sample are

$$
\begin{aligned}
& d \varepsilon_{\mathrm{R}}=-\frac{d h_{\mathrm{R}}}{H_{\mathrm{R}}}, \\
& d \varepsilon_{\mathrm{C}}=-\frac{d h_{\mathrm{C}}}{H_{\mathrm{C}}} .
\end{aligned}
$$

Equations (9)-(12) were solved simultaneously to obtain the respective stresses of the rock and coal in the coal-rock combination as follows:

$$
\left\{\begin{array}{l}
\sigma_{\mathrm{R}}=-\frac{m_{\mathrm{R}} E_{\mathrm{R}}}{H_{R}} h_{\mathrm{R}}+C_{1}, \\
\sigma_{\mathrm{C}}=-\frac{m_{\mathrm{C}} E_{\mathrm{C}}}{H_{\mathrm{C}}} h_{\mathrm{R}}+C_{2},
\end{array}\right.
$$

where $C_{1}$ and $C_{2}$ are integration constants.

When the external force $F$ is zero, under the initial conditions, $h_{\mathrm{R}}=H_{\mathrm{R}}$ and $h_{\mathrm{c}}=H_{\mathrm{c}}$, based on which $C_{1}=m_{\mathrm{R}} E_{\mathrm{R}}$ and $C_{2}=m_{\mathrm{C}} E_{\mathrm{C}}$. Substitution into Equation (13) leads to the correction parameters of the displacements, strains, and elastic moduli of the rock and coal in the combination sample structure as follows:

$$
\begin{aligned}
& \left\{\begin{array}{l}
\Delta R=h_{\mathrm{R}}-H_{\mathrm{R}}=-H_{\mathrm{R}} \frac{\sigma_{\mathrm{R}}}{m_{\mathrm{R}} E_{\mathrm{R}}}, \\
\Delta C=h_{\mathrm{C}}-H_{\mathrm{C}}=-H_{\mathrm{C}} \frac{\sigma_{\mathrm{C}}}{m_{\mathrm{C}} E_{\mathrm{C}}} .
\end{array}\right. \\
& \left\{\begin{array}{l}
\varepsilon_{\mathrm{R}}=\frac{\Delta R}{H_{\mathrm{R}}}=\frac{h_{\mathrm{R}}-H_{\mathrm{R}}}{H_{\mathrm{R}}}=-\frac{\sigma_{R}}{m_{\mathrm{R}} E_{\mathrm{R}}}, \\
\varepsilon_{\mathrm{C}}=\frac{\Delta C}{H_{\mathrm{C}}}=\frac{h_{\mathrm{C}}-H_{\mathrm{C}}}{H_{\mathrm{C}}}=-\frac{\sigma_{\mathrm{C}}}{m_{\mathrm{C}} E_{\mathrm{C}}},
\end{array}\right. \\
& \left\{\begin{array}{l}
m_{\mathrm{R}}=-\frac{\sigma_{\mathrm{R}}}{\varepsilon_{R} E_{R}}, \\
m_{\mathrm{C}}=-\frac{\sigma_{\mathrm{C}}}{\varepsilon_{\mathrm{C}} E_{\mathrm{C}}} .
\end{array}\right.
\end{aligned}
$$

\section{Mechanical Experiment and Analysis of the Instability of the Coal-Rock Combination System}

4.1. Experimental Design. The coal samples and rock samples required for the experiment were both collected from the Pingdingshan No. 5 Coal Mine. The coal-bearing strata in this mine are 556 to $1090 \mathrm{~m}$ thick, with an average of $796 \mathrm{~m}$. There are 21 to 56 coal-bearing seams, including 8 minable and partially minable seams. Among them, the roof of the Geng 20 coal seam is dominated by sandstone and sandy mudstone, and its floor lithology is mostly sandstone and limestone. To meet the experimental needs, rock specimens with three different lithologies (i.e., coarse sandstone, fine sandstone, and siltstone) and raw coal specimens were prepared. According to their lithologies and coal-rock height ratios, two groups of different combination samples were prepared. Group A contained combination samples with different lithologies and with coal and rock heights of $50 \mathrm{~mm}$ each, as shown in Figure 6(a). Group B contained samples formed by bonding the siltstone specimens to the raw coal specimens. The ratios of the heights of the rock and coal in the specimens were $1: 1,1.5: 1$, and $2: 1$, and the total height of each sample was $100 \mathrm{~mm}$, as shown in Figure 6(b).

The experiments were divided into 2 sets, as shown in Table 1. In set A, uniaxial compression tests were carried out on combination samples with three different lithologies, and the experiments were repeated three times for each type of combination sample. The experiments were numbered A11 through A33, for a total of 9 experiments. In set B, uniaxial compression tests were conducted on combination samples with three different height ratios, and the experiments were repeated three times for each height ratio. The experiments were numbered B11 through B33, for to a total of 9 experiments.

4.2. Experimental Results. A TAW-2000 microcomputercontrolled rock triaxial testing machine was used to carry out the uniaxial compression tests on the coal-rock combination samples, and a DH3818Y static strain tester was used to monitor the strain of the samples. The test equipment is shown in Figure 7. Figure 8 shows the stress-strain curve of the coarse sandstone-coal combination sample (A11). Figures 9(a)-9(c) show the failure modes of the coal-rock combination sample structures with different lithologies. Figures 10(a)-10(c) show the failure modes of the coal-rock combination sample structures with different height ratios.

As can be seen from Figure 9, when the coarse sandstone-raw coal combination samples underwent instability failure, a few cracks appeared in the rock part at the interface, and the coal basically maintained its integrity. The failure was concentrated in the pieces of lump coal, which still retained a certain amount of integrity. The fine sandstone-raw coal combination samples and the siltstone-raw coal combination samples were damaged severely. The coal was cut through, the damaged coal was in the form of small blocks and particles, and there were no notable cracks in the rock parts. Figure 10 shows that the structure of the combination samples with a rock-coal height ratio of $2: 1$ suffered the 

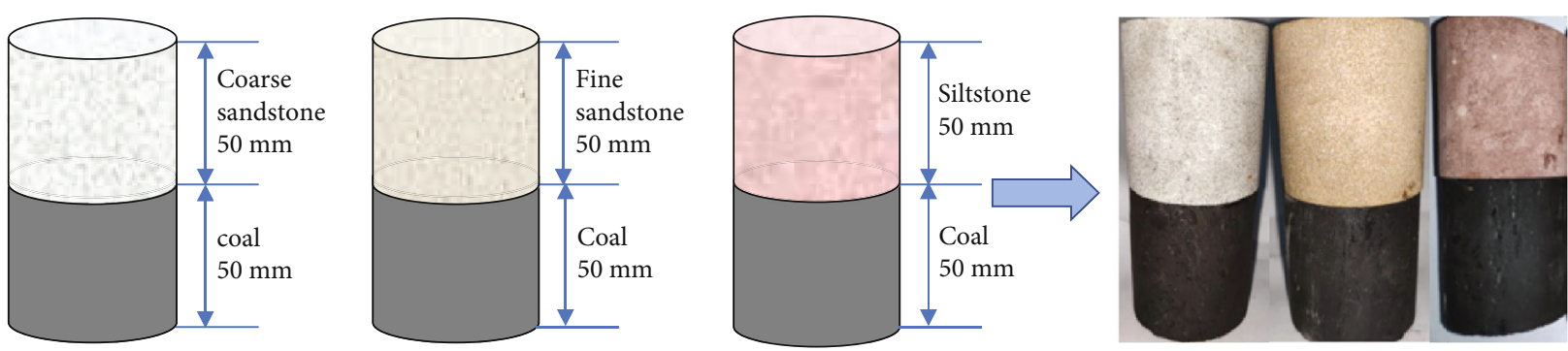

(a)
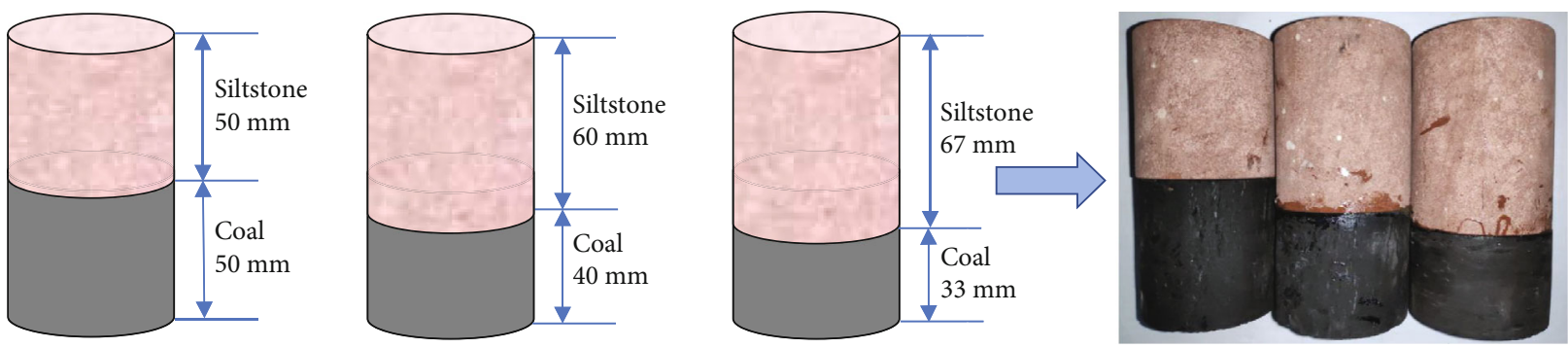

(b)

FIGURE 6: Schematic diagram of the deformation of the coal-rock combination under an external force: (a) combination samples with different lithologies; (b) combination samples with different height ratios.

TABle 1: Experimental design.

\begin{tabular}{lccccccc}
\hline \multicolumn{3}{c}{ Set A: samples with different lithologies } & \multicolumn{4}{c}{ Set B: samples with different height ratios } \\
\hline Coarse sandstone-coal & A11 & A12 & A13 & Siltstone-coal height ratio 1:1 & B11 & B12 & B13 \\
Fine sandstone-coal & A21 & A22 & A23 & Siltstone-coal height ratio 1.5:1 & B21 & B22 & B23 \\
Siltstone-coal & A31 & A32 & A33 & Siltstone-coal height ratio 2:1 & B31 & B32 & B33 \\
\hline
\end{tabular}

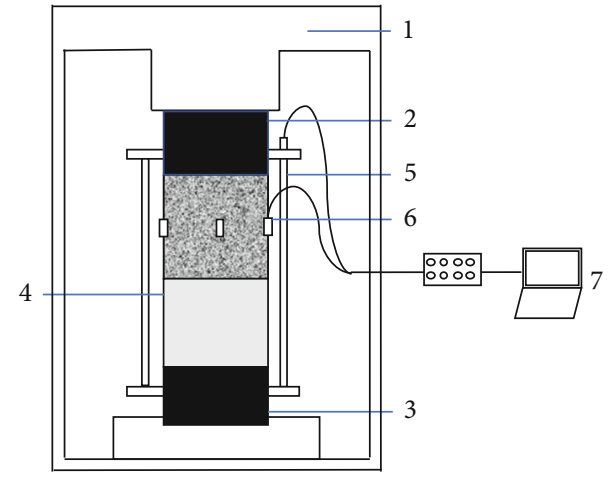

Figure 7: The test equipment. 1 the TAW-2000 testing machine, 2 upper indenter, 3 lower indenter, 4 coal-rock combination sample, 5 extensometer, 6 strain gauges, and 7 the DH3818Y static strain tester.

most severe damage. The combination structure was completely destroyed, and the coal in the structure was shattered into powder. The damage to the structure of the combination samples with a rock-coal height ratio of $1.5: 1$ manifested as a large number of longitudinal cracks on the surface of the coal, resulting in the coal being cut through. Due to its internal failure, it no longer had a bearing capacity,

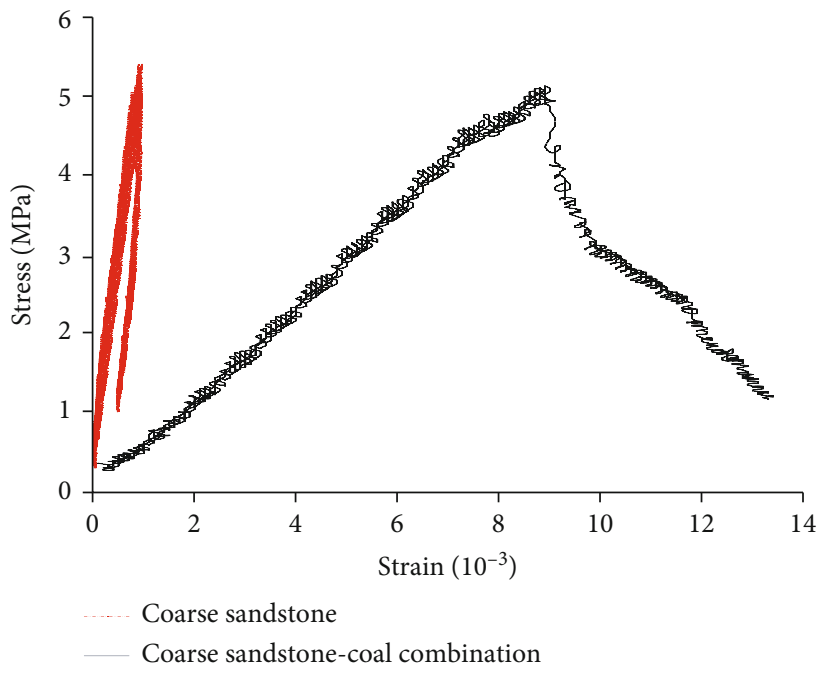

FIGURE 8: The stress-strain curve of the coarse sandstone-coal combination sample (A11).

and obvious dilatancy phenomenon occurred in the coal part under compression. The damage to the combination sample structures with a rock-coal height ratio of $1: 1$ was mainly manifested as a few pieces of coal falling off of the structure. 


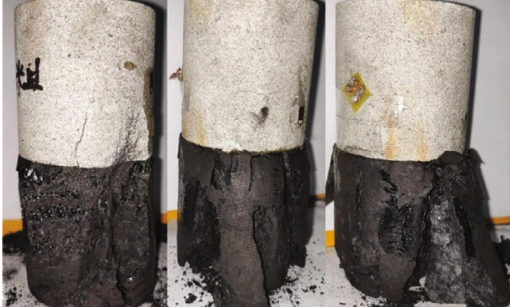

(a)

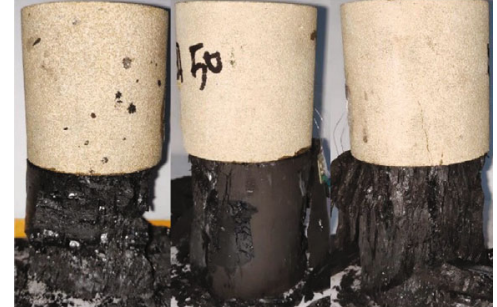

(b)

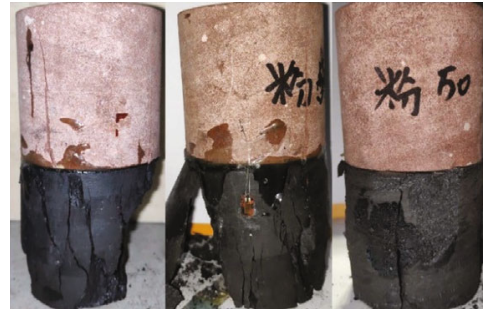

(c)

Figure 9: The failure modes of the coal-rock combination sample structures with different lithologies: (a) coarse sandstone-coal; (b) fine sandstone-coal; (c) siltstone-coal.

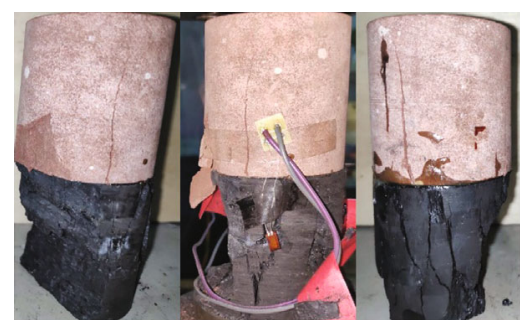

(a)

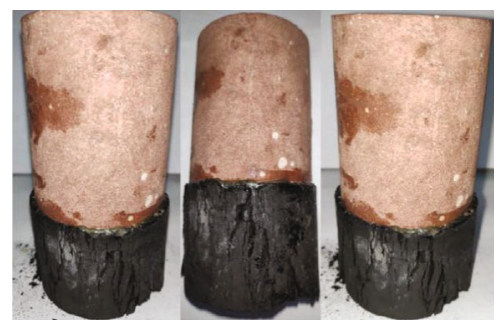

(b)

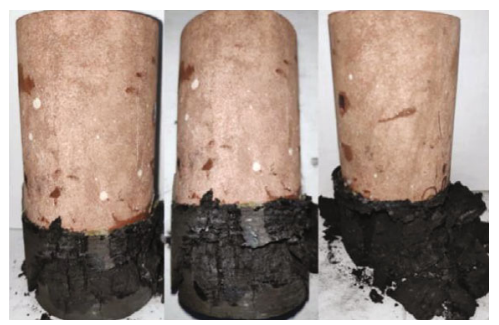

(c)

FIGURE 10: The failure modes of the coal-rock combination sample structures with different height ratios: (a) siltstone-coal height ratio $1: 1$; (b) siltstone-coal height ratio $1.5: 1$; (c) siltstone-coal height ratio $2: 1$.

TABLE 2: The critical equilibrium values for the failure of the two types of coal-rock combination sample structures with different lithologies and different height ratios.

\begin{tabular}{lccccccc}
\hline Set A & $m_{R} E_{a} S_{a} / l_{a}$ & $m_{c} E_{b} S_{b} / l_{b}$ & Difference & Set B & $m_{R} E_{a} S_{a} / l_{a}$ & $m_{c} E_{b} S_{b} / l_{b}$ & Difference \\
\hline A11 & 153.490 & 156.324 & -2.834 & B11 & 200.054 & 200.525 \\
A12 & 153.581 & 156.110 & -2.529 & B12 & 209.201 & 209.669 & -0.471 \\
A13 & 157.802 & 159.573 & -1.771 & B13 & 206.072 & 206.508 \\
A21 & 180.778 & 181.845 & -1.067 & B21 & 244.145 & 244.436 & -0.436 \\
A22 & 175.587 & 176.664 & -1.077 & B22 & 241.743 & 241.945 & -0.291 \\
A23 & 178.998 & 180.079 & -1.081 & B23 & 245.242 & 245.455 & -0.202 \\
A31 & 197.935 & 198.566 & -0.631 & B31 & 301.323 & 301.446 & -0.1213 \\
A32 & 195.588 & 196.289 & -0.701 & B32 & 305.901 & 306.083 & -0.182 \\
A33 & 196.145 & 196.799 & -0.654 & B33 & 304.851 & 304.983 & -0.132 \\
\hline
\end{tabular}

The coal could still maintain the combination structure to a certain extent after the failure of the coal, and the coal still had some bearing capacity.

The difference in the structural failure modes of the two different types of combination samples is mainly reflected in the failure of the coal. For the combination sample structures of different lithologies, a higher rock strength corresponded to a larger elastic modulus, so more elastic strain energy could be accumulated during its compression deformation. The elastic strain energy accumulated in the rock was released into the coal at the moment when the sample underwent instability failure, resulting in the differences in the failure modes of the coal. For the combination sample structures with different height ratios, a higher rock content corresponded to a higher sample strength, so more elastic strain energy accumulated during the rock compression process. When the combination sample failed, the deformation of the coal part was more violently and significant.

4.3. Critical Condition Verification Analysis. By substituting the experimental stress and strain data for the coal-rock combination structures used in the uniaxial compression tests into Equation (16), the correction parameters $m_{\mathrm{C}}$ and $m_{\mathrm{R}}$ for the elastic moduli of the coal and rock, respectively, were obtained. Then, these were substituted into Equation (8) to obtain the overall displacement-load function relationship of the corrected combination sample structures composed of rock block $a$ and coal block $b$ and the critical 
conditions for the failure of the corrected combination samples, as shown in Equation (17).

$$
\sigma= \begin{cases}\frac{m_{\mathrm{R}} E_{a} m_{\mathrm{c}} E_{b} S_{b}}{m_{\mathrm{R}} E_{a} S_{a} l_{b}+m_{\mathrm{c}} E_{b} S_{b} l_{a}} u, & -\infty<\varepsilon_{b} \leq \varepsilon_{\mathrm{c} b}, \\ \frac{m_{\mathrm{R}} E_{a}}{m_{\mathrm{c}} E_{b}}\left(\frac{\left(m_{\mathrm{c}} E_{b} S_{b} \sigma_{\mathrm{c} b} / l_{a}\right)+\left(m_{\mathrm{c}} E_{b} S_{b} \sigma_{\mathrm{c} b} / l_{a}\right)}{\left(m_{\mathrm{R}} E_{a} S_{a} / l_{a}\right)-\left(m_{\mathrm{c}} E_{b} S_{b} / l_{b}\right)}-\frac{m_{\mathrm{c}}{ }^{2} E_{b}{ }^{2} S_{b} / l_{a} l_{b}}{\left(m_{\mathrm{R}} E_{a} S_{a} / l_{a}\right)-\left(m_{\mathrm{c}} E_{b} S_{b} / l_{b}\right)} u\right), & \varepsilon_{\mathrm{c} b}<\varepsilon_{b} \leq \varepsilon_{\mathrm{r} b}, \\ \sigma_{\mathrm{r} b}, & \varepsilon_{\mathrm{r} b}<\varepsilon_{b} \leq+\infty .\end{cases}
$$

$m_{\mathrm{R}} E_{a} S_{a} / l_{a}-m_{b} E_{b} S_{b} / l_{b}=0$ indicates that the combination sample structure is in a critical state of limit equilibrium, and the combination structure will fail immediately when the external load increases. $m_{\mathrm{R}} E_{a} S_{a} / l_{a}-m_{b} E_{b} S_{b} / l_{b}<0$ indicates that the combination sample structure is in the failure state, and the coal part of the structure is subjected to the combined actions of the external work and rebound energy of the rock in the system. In the case of $m_{\mathrm{R}} E_{a} S_{a} / l_{a}-m_{b} E_{b} S_{b} / l_{b}>0$, if external work is done to the system, the degree of damage done to the combination sample structure will increase, and the system will still have a certain bearing capacity.

Taking the peak failure point of the combination sample as the research object, the coal in the sample at this moment reaches its peak strength and $\varepsilon_{b} \geq \varepsilon_{c b}$, but the rock part is still in the elastic stage. The structural failure characteristics of the combination sample expressed by Equation (17) are satisfied. Therefore, the critical equilibrium values for the failure of the two types of coal-rock combination sample structures with different lithologies and different height ratios can be calculated, as shown in Table 2.

As can be seen from Table 2, the critical equilibrium values of the different combination samples are all negative, and they approach 0 as the rock strength and the proportion of rock in the combination samples increase, indicating that the combination samples failed under the combined actions of the external work and the rebound energy of the rock. When the load on the system reached the maximum that the coal could withstand, the strain of the coal increased, exceeded its uniaxial compressive strength, and reached the peak strain, at which time the combination structure underwent instability failure. At this moment, the rock was still in its elastic stage; and the strain increased with increasing stress, reaching its maximum value at the peak point of the system's strain. After that, the strain of the rock decreased, exhibiting a trend opposite to that of the coal. The strain characteristics that the coal and rock exhibited at the system's strain peak point and in the moments thereafter indicate that the rock exerts rebound energy on the coal, which is consistent with the mechanical phenomenon represented by the calculated critical equilibrium value being less than 0 .

\section{Energy Transfer Characteristics during the Instability of the Coal-Rock System}

5.1. Elastic Energy Test and Energy Transfer Analysis of the Coal-Rock Combination. The energy evolution of the loaded coal-rock system can be divided into three main processes: energy input, energy accumulation, and energy dissipation. In the loading process, without considering the damping dissipation and heat exchange, the energy input is mainly derived from the work done by the experimental machine on the combination sample. Part of the input energy is accumulated in the combination sample in the form of reversible elastic energy, and the other part is dissipated in the form of plastic deformation energy and damage energy, which is irreversible. When the accumulated elastic strain energy in the combination sample reaches a certain extent, the coal, which has a much smaller elastic modulus than the rock, undergoes instability failure due as it reaches the limit of its bearing capacity. Then, the rock part of the combination sample exhibits the passive unloading phenomenon, the stress and strain of the rock decrease, and the rock releases the stored elastic strain energy into the system. This part of the energy acts on the coal, aggravating the damage to the coal and increasing the degree of crushing. The coal part undergoes instability failure under the joint actions of the energy accumulated in the coal itself and the elastic strain energy transferred to the coal during the passive unloading of the rock part.

Based on the stress-strain curves of the rock part and the overall combination sample of the coal-rock combination sample structure under uniaxial compression until its failure (Figure 11), the following energy values are obtained: the energy accumulated before the peak of the corresponding combination sample $\left(E_{1}\right)$, the energy consumed by the failure of the combination sample $\left(E_{2}\right)$, the elastic energy accumulated by the rock part during uniaxial compression $(U)$, and the elastic strain energy transferred to the coal during the passive unloading of the rock part $\left(U_{1}\right)$, as shown in the following equation:

$$
\left\{\begin{array}{l}
E_{1}=V_{\text {combination }} \int_{\mathrm{OBI}} \sigma \mathrm{d} \varepsilon=S_{\mathrm{OBI}} V_{\text {combination }}, \\
E_{2}=V_{\text {combination }} \int_{\mathrm{BIKE}} \sigma \mathrm{d} \varepsilon=S_{\mathrm{BIKE}} V_{\text {combination }}, \\
U=V_{\text {rock }} \int_{\mathrm{OAH}} \sigma \mathrm{d} \varepsilon=S_{\mathrm{OAH}} V_{\text {rock }}, \\
U_{1}=V_{\text {rock }} \int_{\mathrm{NAD}} \sigma \mathrm{d} \varepsilon=S_{\mathrm{NAD}} V_{\text {rock }},
\end{array}\right.
$$




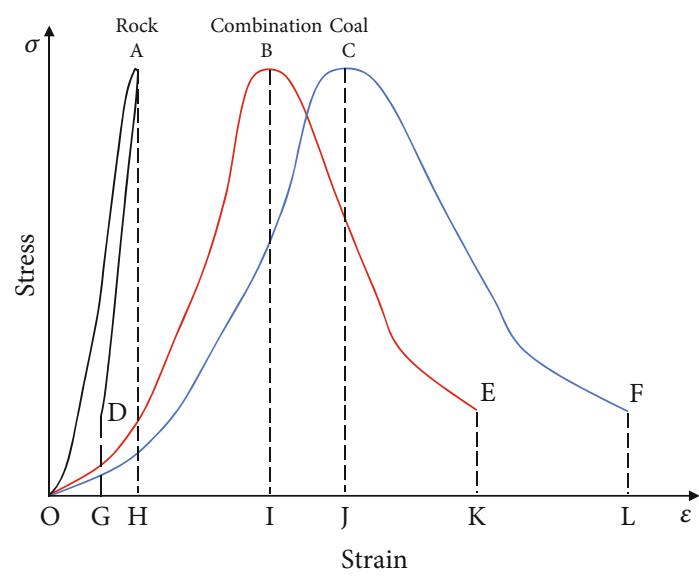

(a) The stress-strain curves of the overall combination

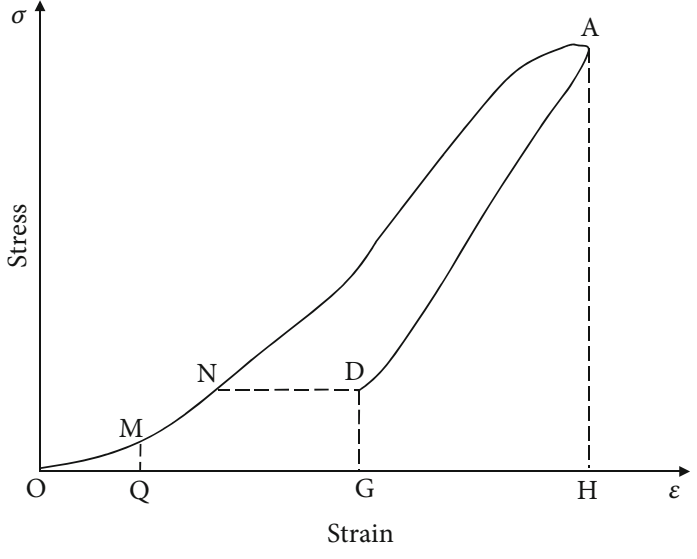

(b) The stress-strain curves of the rock part

FIGURE 11: The stress-strain curves of the rock part and the overall combination sample of the coal-rock combination sample structure under uniaxial compression until its failure.

TABLE 3: The calculation results of each research index.

\begin{tabular}{|c|c|c|c|c|c|c|c|}
\hline No. & $U_{1}(\mathrm{~J})$ & $U(\mathrm{~J})$ & $E_{1}(\mathrm{~J})$ & $U_{1} / U$ & Average $U_{1} / U$ & $U_{1} /\left(E_{1}-U+U_{1}\right)$ & Average $U_{1} /\left(E_{1}-U+U_{1}\right)$ \\
\hline A11 & 0.30537 & 1.16180 & 8.53295 & $26.28 \%$ & & $3.98 \%$ & \\
\hline A12 & 0.28221 & 1.09508 & 7.72440 & $25.77 \%$ & $26 \%$ & $4.08 \%$ & $4.0 \%$ \\
\hline A13 & 0.27632 & 1.08330 & 7.70085 & $25.51 \%$ & & $4.01 \%$ & \\
\hline A 21 & 0.32342 & 1.15003 & 8.64285 & $28.12 \%$ & & $4.14 \%$ & \\
\hline A22 & 0.32146 & 1.21675 & 8.63108 & $26.42 \%$ & $28 \%$ & $4.16 \%$ & $4.1 \%$ \\
\hline $\mathrm{A} 23$ & 0.34893 & 1.17358 & 9.44748 & $29.73 \%$ & & $4.05 \%$ & \\
\hline A 31 & 0.52988 & 1.31488 & 11.51988 & $40.30 \%$ & & $4.94 \%$ & \\
\hline A 32 & 0.54558 & 1.37375 & 12.17143 & $39.71 \%$ & $40 \%$ & $4.81 \%$ & $4.9 \%$ \\
\hline A33 & 0.50240 & 1.25993 & 11.00178 & $39.88 \%$ & & $4.90 \%$ & \\
\hline B11 & 0.54558 & 1.31488 & 12.06545 & $41.49 \%$ & & $4.83 \%$ & \\
\hline B12 & 0.53380 & 1.33843 & 11.85350 & $39.88 \%$ & $41 \%$ & $4.83 \%$ & $4.8 \%$ \\
\hline $\mathrm{B} 13$ & 0.54165 & 1.29918 & 12.20675 & $41.69 \%$ & & $4.73 \%$ & \\
\hline B21 & 0.79599 & 1.77567 & 10.86754 & $44.83 \%$ & & $8.05 \%$ & \\
\hline B22 & 0.81483 & 1.73799 & 10.99314 & $46.88 \%$ & $46 \%$ & $8.09 \%$ & $8.1 \%$ \\
\hline B23 & 0.79128 & 1.74742 & 10.74508 & $45.28 \%$ & & $8.08 \%$ & \\
\hline B31 & 1.10429 & 2.09867 & 9.65715 & $52.62 \%$ & & $12.75 \%$ & \\
\hline B32 & 1.182794 & 2.15624 & 10.18043186 & $54.85 \%$ & $53 \%$ & $12.85 \%$ & $12.4 \%$ \\
\hline B33 & 1.03625 & 2.04634 & 9.89786 & $50.64 \%$ & & $11.66 \%$ & \\
\hline
\end{tabular}

where $S$ is the corresponding area under the stress-strain curve and $V$ is the volume of the corresponding structure.

To describe the energy characteristics and transfer patterns, including their relationships with the failure state and failure severity, of the different combination samples during failure, the following indicators are proposed:

(1) $U_{1}$ intuitively reflects the influence of the elastic strain energy of the rock on the instability failure of the coal

(2) $U_{1} / U$ reflects the difference in the ability of the rock parts of the different combination samples to release elastic strain energy
(3) $U_{1} /\left(E_{1}-U+U_{1}\right)$ reflects the proportion of the energy contributed by the elastic strain energy released by the rock during the failure of the coal-rock combination

The indicators were calculated based on Figure 10 and Equation (18), and the specific results are shown in Table 3.

The following can be seen from Table 3:

(1) During the failure process of the coal-rock combination, the greater the stored elastic strain energy released into the system by the rock $\left(U_{1}\right)$, the higher the crushing degree of the coal after the failure of the combination structure. For the coal-rock combination samples of different lithologies, the greater the 


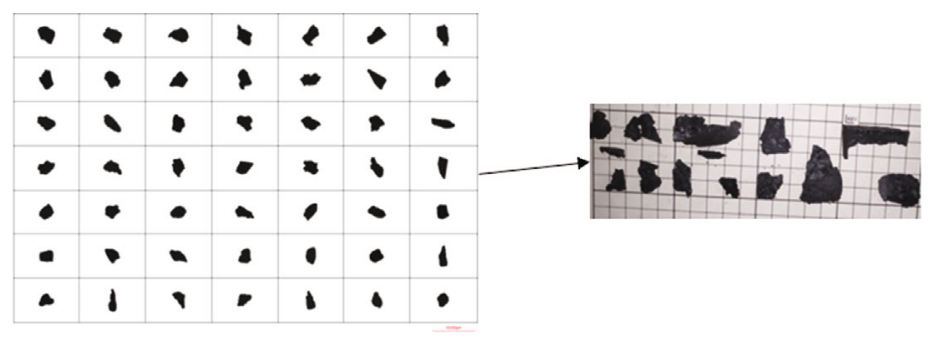

(a) Coarse sandstone-coal A11

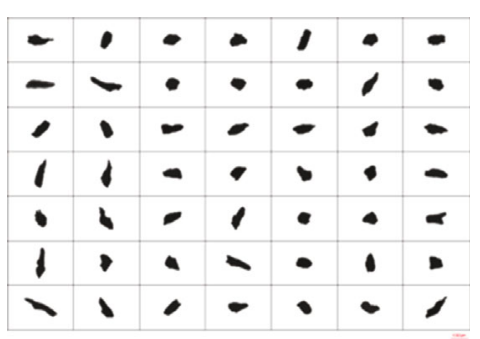

(b) Fine sandstone-coal A21

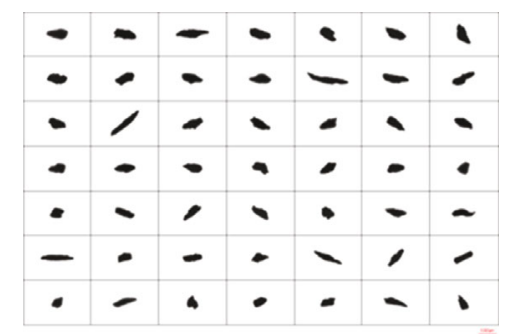

(c) Siltstone-coal A31

FIGURE 12: The particle size statistics of the crushed coal samples after the failure of the different lithology combination structures.

strength of the roof rock, the greater the stored elastic strain energy released into the system by the rock. For the coal-rock combination samples with different height ratios, the smaller the coal-rock height ratio, the greater the stored elastic strain energy released into the system by the rock

(2) For the different combination specimens, the stored elastic strain energy released into the system by the rock accounts for a large proportion of the energy accumulated in the rock $=(U 1 / U)$, reaching $26 \%$ to $53 \%$, whereas this part of the energy contributes a relatively small amount to the energy during the failure of the coal-rock combination $\left(U_{1} /\left(E_{1}-U+U_{1}\right)\right)$, only accounting for approximately $4 \%$ to $12.4 \%$. During the failure process of the coal-rock combination, as the strength of the roof rock increased, $U_{1} / U$ increased, whereas the change in $U_{1} /\left(E_{1}-U+U_{1}\right)$ was not significant. As the coal-rock height ratio decreased, $U_{1} / U$ increased, and $U_{1} /\left(E_{1}-U+U_{1}\right)$ increased significantly. This indicates that, relative to the strength of the roof rock of the coal-rock combination, the coal-rock height ratio of the coal-rock combination plays a greater role in the failure of the coal-rock combination.

5.2. Test of the Crushing Degree of the Coal Sample. The compression failure of the combination samples under uniaxial conditions was a process involving energy accumulation, transfer, and release. To analyze the patterns of energy transfer and release during this process, it is necessary to study the crushing degree of the coal after failure. In essence, the crushing of the combination sample is a process in which, under the combined actions of the energy accumulated in the sample and the elastic strain energy released by the upper rock part, the coal is crushed into smaller pieces, creating new surfaces that separate the pieces from the original body. Therefore, there is an inevitable relationship between the sum of the elastic strain energy released by the rock and the energy accumulated in the coal (i.e., the crushing energy) and the new surface [42]. By analyzing the particle distribution of the crushed coal samples after the failure of the different combination samples and the crushing degree of the different combination samples, the newly added surface areas of the different combination samples were calculated and the relationship between the newly added surface area and the crushing energy was obtained. The particle size statistics of the crushed coal samples after the failure of the different combination structures were determined, and the typical results are shown in Figure 12. From the particle size and microscopic morphology, it can be seen that most of the broken coal-like particles are close to spherical or ellipsoidal, with only a few irregular shapes.

According to the new surface theory $[43,44]$, the coal crushing energy was all used to create new surfaces, the area of which was generated by the crushed coal:

$$
S_{\mathrm{New}}=\frac{6 m}{\rho d_{\mathrm{Z}}}
$$

where $S_{\mathrm{New}}$ is the newly added surface area of the crushed coal, $m$ is the mass of the coal, $\rho$ is the density of the coal, and $d_{\mathrm{Z}}$ is the converted diameter of the coal.

The newly added surface area of the different combination samples was calculated by Equation (19), as shown in Table 4.

As can be seen from Table 4, for the different coal-rock combination samples tested in the experiments, the mass of the crushed coal sample was relatively small, accounting for less than $5 \%$ of the total coal in the combination sample. The newly added surface areas of the different combination samples, which were provided by the crushed coal, reflect the crushing conditions of the samples. The larger the newly 
TABLE 4: The newly added surface area of the different combination samples.

\begin{tabular}{lccccc}
\hline No. & $\begin{array}{c}\text { Coal weight } \\
(\mathrm{g})\end{array}$ & $\begin{array}{c}\text { Crushed coal weight } \\
(\mathrm{g})\end{array}$ & $\begin{array}{c}\text { Crushed coal weight/coal weight } \\
(\%)\end{array}$ & $\begin{array}{c}\text { Converted diameter } \\
(\mathrm{mm})\end{array}$ & $\begin{array}{c}\text { Newly added surface area } \\
\left(\mathrm{mm}^{2}\right)\end{array}$ \\
\hline A11 & 127.0 & 6.3 & 4.96 & 1.6976 & 346813.148 \\
$\mathrm{~A} 12$ & 127.1 & 5.3 & 4.16 & 1.5867 & 371053.129 \\
$\mathrm{~A} 13$ & 127.8 & 6.1 & 4.77 & 1.5487 & 380157.551 \\
$\mathrm{~A} 21$ & 126.4 & 5.2 & 4.11 & 1.0826 & 543829.669 \\
$\mathrm{~A} 22$ & 126.4 & 4.8 & 3.79 & 1.1287 & 521617.790 \\
$\mathrm{~A} 23$ & 126.3 & 4.7 & 3.72 & 0.9828 & 599053.724 \\
$\mathrm{~A} 31$ & 126.2 & 4.6 & 3.64 & 0.8277 & 711308.445 \\
$\mathrm{~A} 32$ & 126.7 & 4.3 & 3.39 & 0.8177 & 720007.338 \\
A33 & 126.3 & 4.1 & 3.24 & 0.7719 & 762728.333 \\
B11 & 127.3 & 5.1 & 4.00 & 0.7828 & 752107.818 \\
B12 & 127.4 & 4.9 & 3.84 & 0.7961 & 739542.771 \\
B13 & 127.2 & 5.0 & 3.93 & 0.7840 & 750956.633 \\
B21 & 101.6 & 4.8 & 4.72 & 0.6019 & 782522.014 \\
B22 & 99.2 & 4.6 & 4.63 & 0.5979 & 787757.150 \\
B23 & 100.3 & 4.7 & 4.68 & 0.5778 & 815160.955 \\
B31 & 82.8 & 4.1 & 4.95 & 0.4423 & 878532.670 \\
B32 & 80.1 & 3.8 & 4.74 & 0.4379 & 887360.128 \\
B33 & 79.9 & 3.4 & 4.25 & 0.4308 & 901984.680 \\
\hline
\end{tabular}

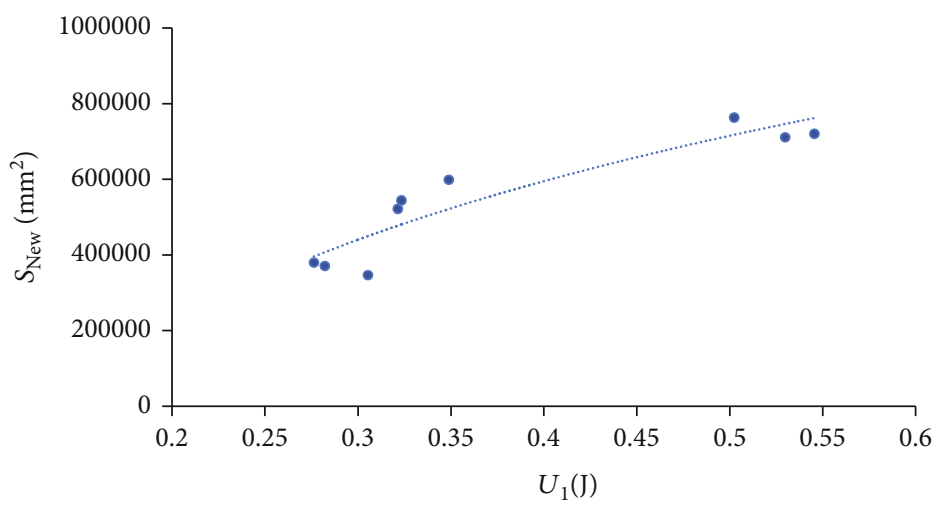

FIGURE 13: The relationship between $S_{\mathrm{New}}$ and $U_{1}$ of the different lithology combination structures.

added surface area, the higher the crushing degree of the coal, that is, the more severe the degree of instability failure.

To further illustrate the aggravating effect of the rock elastic energy on the failure of the coal, the newly added surface area was selected as the research object, and for the coal-rock combinations with different roof lithologies, the relationship between the newly added surface area and the stored elastic strain energy released into the system by the rock $\left(U_{1}\right)$ was analyzed. The energy characteristics of the combination samples during instability failure under uniaxial conditions were analyzed from the perspective of coal crushing, as shown in Figure 13.

Figure 13 shows that as the rock strength of the coal-rock combination increased, the $U_{1}$ increased, which increased the crushing degree of the sample, leading to an increase in $S_{\mathrm{New}}$ of the crushed coal. Furthermore, there is a logarithmic relationship between the two, and the fitting relationship is $S_{\mathrm{New}}=537808 \ln \left(U_{1}\right)+1087600$.

\section{Conclusions}

(1) Based on the analysis of the mechanical behaviors of the combination structures under uniaxial conditions, the relationship between the value of the critical equilibrium conditions of the sample $\left(m_{\mathrm{R}} E_{a} S_{a} / l_{a}-m_{\mathrm{c}} E_{b} S_{b} / l_{b}\right)$ and the theoretical peak failure point value 0 is proposed and verified using experimental data. If the value is less than 0 , the sample has undergone instability failure. If the value is greater than 0 , the sample has not reached the limit state. If the value is 0 , the sample is in a state of limit 
equilibrium, and an increase in the external load will cause the sample to undergo instability failure

(2) The combination samples underwent instability failure under the combined actions of the external load and the rock's elastic energy. The stored elastic strain energy that was released into the combination sample system by the rock $\left(U_{1}\right)$ accounts for approximately $26 \%$ to $53 \%$ of the energy accumulated by the rock, and the proportion of energy contributed to the failure of the coal-rock combination $\left(U_{1} /\left(E_{1}-U+U_{1}\right)\right)$ is approximately $4 \%$ to $12.4 \%$. The values of these two energies are greater for the combination samples with different height ratios than for the combination samples with different lithologies

(3) The crushing degree of the coal characterizes the severity of the instability failure of the combination sample. The failure severity of the combination sample and the crushing degree of the coal are related to the ability of the rock in the sample to release the stored elastic strain energy into the combination sample system $\left(U_{1}\right)$. The larger the $U_{1}$ value, the larger the increased surface area generated by the coal after the failure of the combination sample, and the more severely the coal is crushed, which leads to a higher degree of sample failure. Moreover, the stored elastic strain energy that is released into the combination sample system by the rock is logarithmically related to the increase in surface area

\section{Data Availability}

The data used to support the findings of this study are included within the article.

\section{Disclosure}

Meanwhile, the founding sponsors had no role in the design of the study; in the collection, analyses, or interpretation of data; in the writing of the manuscript; and in the decision to publish the results.

\section{Conflicts of Interest}

The authors declare no conflict of interest.

\section{Authors' Contributions}

The manuscript is approved by all authors for publication. All the authors listed have approved the manuscript that is enclosed.

\section{Acknowledgments}

This work is financially supported by the National Natural Science Foundation of China (51874348, 51974358, 51774319, 51574280), Chongqing Science Fund for Distinguished Young Scholars (cstc2019jcyjjqX0019), Science and Technology Innovation and Entrepreneurship Fund of China Coal Technology Engineering Group (2019-TDQN040), Chongqing Science and Technology Innovation Leading Talent Support Program (CSTCCXLJRC201911), and National Key Research and Development Program (2016YFC0801402) which are gratefully acknowledged.

\section{References}

[1] M. C. He, H. P. Xie, S. P. Peng, and Y. D. Jiang, "Study on rock mechanics in deep mining engineering," Chinses Journal of Rock Mechanical and Engineering, vol. 24, no. 16, pp. 28032813, 2005.

[2] H. W. Zhou, H. P. Xie, and J. P. Zuo, "Developments in researches on mechanical behaviors of rocks under the condition of high ground pressure in the depths," Advances in Mechanics, vol. 35, no. 1, pp. 91-97, 2005.

[3] L. C. Dai, Y. B. Liu, J. Cao et al., "A Study on the energy condition and quantitative analysis of the occurrence of a coal and gas outburst," Shock and Vibration, vol. 2019, Article ID 8651353, 13 pages, 2019.

[4] J. G. Li, Q. T. Hu, M. G. Yu, X. L. Li, J. Hu, and H. M. Yang, "Acoustic emission monitoring technology for coal and gas outburst," Energy Science \& Engineering, vol. 7, no. 2, pp. 443-456, 2019.

[5] G. C. Wen, H. T. Sun, J. Cao, Y. B. Liu, L. C. Dai, and B. Wang, "Simulation experiment system of coal and gas dynamic disaster in deep mine and its application in accident analysis," Journal of China Coal Society, vol. 45, no. 1, pp. 223-231, 2020.

[6] B. B. Gao, "Research status and prospect of compound dynamic disaster of deep mining in coal mine," Safety in Coal Mines, vol. 44, no. 11, pp. 175-178, 2013.

[7] F. Du, K. Wang, Y. Y. Guo, G. D. Wang, L. Wang, and Y. H. Wang, "The mechanism of rockburst-outburst coupling disaster considering the coal-rock combination: an experiment study," Geomechanics and Engineering, vol. 22, no. 3, pp. 255-264, 2020.

[8] N. G. W. Cook, "A note on rock burst considered as a problem of stability," Journal of the Southern African Institute of Mining and Metallurgy, vol. 65, pp. 437-446, 1965.

[9] И. М. Петухов, "Theory and practice of preventing rock burst," Safety in Coal Mines, vol. 5, pp. 39-40, 1988.

[10] Z. F. Zhu, "Research report of the laboratory of rock burst in Fushun Longfeng mine-study on using coal (rock) stiffness to establish impact index," Journal of Fuxin Mining Institute, vol. S1, pp. 43-56, 1985.

[11] M. T. Zhang, Z. H. Xu, Y. S. Pan, and Y. S. Zhao, “A united instability theory on coal(rock) burst and outburst," Journal of China Coal Society, vol. 16, no. 4, pp. 48-53, 1991.

[12] Y.S. Pan, "Integrated study on compound dynamic disaster of coal-gas outburst and rockburst," Journal of China Coal Society, vol. 41, no. 1, pp. 105-112, 2016.

[13] Z. Wang, G. Z. Yin, Q. T. Hu, and H. W. Jin, "Inducing and transforming conditions from rockburst to coal-gas outburst in a high gassy coal seam," Journal of Mining and Safety Engineering, vol. 27, no. 4, pp. 572-575,580, 2010.

[14] T. Li, M. F. Cai, J. A. Wang, D. C. Li, and J. Liu, "Discussion on relativity between rockburst and gas in deep exploitation," Journal of China Coal Society, vol. 30, no. 5, pp. 20-25, 2005.

[15] S. Y. Li, X. S. He, K. Pan et al., "Relationship between mining seismicity and gas outburst in coal mine-some scientific 
questions of mining safety," Physics, vol. 36, no. 2, pp. 136$145,2007$.

[16] Y. Liu, C. P. Lu, B. Liu, Z. Y. Xiao, and H. Zhang, "Slip and instability mechanisms of coal-rock parting-coal structure (CRCS) under coupled dynamic and static loading," Energy Science \& Engineering, vol. 7, no. 6, pp. 2703-2719, 2019.

[17] Q. T. Hu, S. N. Zhou, and X. Q. Zhou, "Mechanical mechanism of coal and gas outburst process," Journal of China Coal Society, vol. 33, no. 12, pp. 1368-1372, 2008.

[18] G. Z. Yin, X. Li, J. Lu, and M. H. Li, "Disaster causing mechanism of compound dynamic disaster in deep mining under static and dynamic load conditions," Journal of China Coal Society, vol. 42, no. 9, pp. 2316-2326, 2017.

[19] L. M. Dou, C. P. Lu, Z. L. Mou, Y. H. Qin, and J. M. Yao, "Intensity weakening theory for rockburst and its application," Journal of China Coal Society, vol. 30, no. 6, pp. 690-694, 2005.

[20] Y. X. Zhao, Y. D. Jiang, J. Zhu, and G. Z. Sun, "Experimental study on precursory information of deformations of coalrock composite samples before failure," Chinese Journal of Rock Mechanics and Engineering, vol. 27, no. 2, pp. 339-346, 2008.

[21] J. P. Zou, Z. F. Wang, H. W. Zhou, J. L. Pei, and J. F. Liu, "Failure behavior of a rock-coal-rock combined body with a weak coal interlayer," International Journal of Mining Science and Technology, vol. 23, no. 6, pp. 907-912, 2013.

[22] J. P. Zou, Y. Chen, J. W. Zhang, J. T. Wang, Y. J. Sun, and G. H. Jiang, "Failure behavior and strength characteristics of coalrock combined body under different confining pressures," Journal of China Coal Society, vol. 41, no. 11, pp. 2706-2713, 2016.

[23] J. P. Zou, Y. Chen, Y. J. Sun, G. H. Jiang, and J. T. Wang, "Investigation on whole failure nonlinear model for deep coal-rock combined bodies," Journal of Mining Science and Technology, vol. 2, no. 1, pp. 17-24, 2017.

[24] C. P. Lu, L. M. Dou, and X. R. Wu, "Experimental research on rules of rockburst tendency evolution and acousticelectromagnetic effects of compound coal-rock samples," Chinese Journal of Rock Mechanics and Engineering, vol. 26, no. 12, pp. 2549-2555, 2007.

[25] J. X. Liu, C. A. Tang, W. C. Zhu, and T. H. Yang, "Rock-coal model for studying the rockburst," Chinese Journal of Geotechnical Engineering, vol. 26, no. 2, pp. 276-280, 2004.

[26] Z. J. Wen, X. Wang, L. J. Chen, G. Lin, and H. L. Zhang, "Size effect on acoustic emission characteristics of coal-rock damage evolution," Advances in Materials Science and Engineering, vol. 2017, Article ID 3472485, 8 pages, 2017.

[27] F. Du, K. Wang, G. D. Wang, Y. F. Jiang, C. P. Xin, and $\mathrm{X}$. Zhang, "Investigation of the acoustic emission characteristics during deformation and failure of gas-bearing coal-rock combined bodies," Journal of Loss Prevention in the Process Industries, vol. 55, pp. 253-266, 2018.

[28] K. Yang, W. J. Liu, L. T. Dou, X. L. Chi, Z. Wei, and Q. Fu, "Experimental investigation into interface effect and progressive instability of coal-rock combined specimen," Journal of China Coal Society, vol. 45, no. 5, pp. 1691-1700, 2020.

[29] Q. X. Qi, Y. S. Pan, H. T. Li et al., "Theoretical basis and key technology of prevention and control of coal-rock dynamic disasters in deep coal mining," Journal of China Coal Society, vol. 45, no. 5, pp. 1567-1584, 2020.

[30] Y. Chen, J. P. Zuo, X. Wei, H. Q. Song, and Y. J. Sun, “Energy nonlinear evolution characteristics of the failure behavior of coal-rock combined body," Chinese Journal of Underground Space and Engineering, vol. 13, no. 1, pp. 124-132, 2017.

[31] L. Yang, F. Q. Gao, X. Q. Wang, and J. Z. Li, "Energy evolution law and failure mechanism of coal-rock combined specimen," Journal of China Coal Society, vol. 44, no. 12, pp. 3894-3902, 2019.

[32] G. B. Chen, Z. H. Qin, G. H. Zhang, T. Li, and J. K. Li, "Law of energy distribution before failure of a loaded coal-rock combined body," Rock and Soil Mechanics, vol. 41, no. 6, pp. 113, 2020.

[33] S. L. Song, X. S. Liu, Y. L. Tan, D. Y. Fan, Q. Ma, and H. L. Wang, "Study on failure modes and energy evolution of coalrock combination under cyclic loading," Shock and Vibration, vol. 2020, Article ID 5731721, 16 pages, 2020.

[34] L. Biolzi, J. F. Labuz, and G. Muciaccia, "A problem of scaling in fracture of damaged rock," International Journal of Rock Mechanics and Mining Sciences, vol. 48, no. 3, pp. 451-457, 2011.

[35] A. Fakhimi and B. Hemami, "Axial splitting of rocks under uniaxial compression," International Journal of Rock Mechanics and Mining Sciences, vol. 79, no. 10, pp. 124-134, 2015.

[36] B. Mishra and D. Nie, "Experimental investigation of the effect of change in control modes on the post-failure behavior of coal and coal measures rock," International Journal of Rock Mechanics and Mining Sciences, vol. 60, pp. 363-369, 2013.

[37] Z. H. Chen, C. A. Tang, and R. Q. Huang, "A double rock sample model for rockbursts," International Journal of Rock Mechanics and Mining Sciences, vol. 34, no. 6, pp. 991-1000, 1997.

[38] H. Liu, J. Rutqvist, and J. G. Berryman, "On the relationship between stress and elastic strain for porous and fractured rock," International Journal of Rock Mechanics and Mining Sciences, vol. 46, no. 2, pp. 289-296, 2009.

[39] L. C. Li, H. H. Liu, and Y. Zhao, "Investigation on nonlinear elastic behavior of rocks based on a two-part Hooke's model," Chinese Journal of Rock Mechanics and Engineering, vol. 31, no. 10, pp. 2119-2126, 2012.

[40] Y. Xue, T. Teng, F. N. Dang, Z. Y. Ma, S. H. Wang, and H. B. Xue, "Productivity analysis of fractured wells in reservoir of hydrogen and carbon based on dual-porosity medium model," International Journal of Hydrogem Energy, vol. 45, no. 39, pp. 20240-20249, 2019.

[41] J. Liu, X. Liang, Y. Xue, K. Yao, and Y. Fu, "Numerical evaluation on multiphase flow and heat transfer during thermal stimulation enhanced shale gas recovery," Applied Thermal Engineering, vol. 178, article 115554, 2020.

[42] M. Li, J. X. Zhang, N. Zhou, and Y. L. Huang, "Effect of particle size on the energy evolution of crushed waste rock in coal mines," Rock Mechanics and Rock Engineering, vol. 50, no. 5, pp. 1347-1354, 2017.

[43] C. Y. Guo, X. F. Xian, X. H. Wu, W. J. Yao, and C. Y. Zhang, "The relationship among rock crushing energy, the Protodyakonov coefficient and rock strength," Journal of Chongqing Jianzhu University, vol. 30, no. 6, pp. 28-31, 2008.

[44] P. Coezkowski, J. Macoekewsli, and S. Bak, "Analysis of energy consumption of crushing processes - comparison of one-stage and two-stage processes," Studia Geotechnica et Mechanica, vol. 39, no. 2, pp. 17-24, 2017. 